Supporting Information for:

\title{
Nanoporous polystyrene containing hydrophilic pores from an ABC
}

\author{
triblock copolymer precursor
}

\author{
Javid Rzayev and Marc A. Hillmyer* \\ Department of Chemistry, University of Minnesota, 207 Pleasant St. SE, Minneapolis,
}

MN 55455-0431

\section{Experimental Section}

Materials. All reagents were used as received unless otherwise noted. 2,2'Azoisobutyronitrile (AIBN) was recrystallized from methanol, D,L-lactide was recrystallized from ethyl acetate. Styrene and N,N-dimethylacrylamide were distilled before use. Toluene was purified by passing through an activated alumina column and then through a supported copper catalyst. ${ }^{1}$ Methylene chloride was purified by distilling from calcium hydride. S-1-Dodecyl-S'-( $\alpha, \alpha$ '-dimethyl- $\alpha$ ' '-acetic acid)trithiocarbonate (1) was synthesized according to the reported procedure. ${ }^{2}$

\section{Polymer Synthesis}

Synthesis of PLA-OH (2). Triethylaluminum (1.0 M in heptane, $0.35 \mathrm{~mL}, 3.5 \times 10^{-4}$ moles) and benzyl alcohol $\left(0.072 \mathrm{~mL}, 6.9 \times 10^{-4}\right.$ moles) were mixed in toluene $(70 \mathrm{~mL})$ in a drybox and stirred for 16 hours at room temperature. D,L-Lactide (10 g, 6.9 $\times 10^{-2}$ moles) was added to the reaction mixture, and the flask was sealed and placed in an oil bath at $90{ }^{\circ} \mathrm{C}$. After 3 hours, the reaction was quenched with $1 \mathrm{~N} \mathrm{HCl}(5 \mathrm{~mL})$ and the contents were precipitated in methanol. The polymer was then redissolved in $\mathrm{CH}_{2} \mathrm{Cl}_{2}$, precipitated in pentane, and dried under vacuum overnight. Yield $=6.7 \mathrm{~g}(67 \%)$. SEC (PS stds): $\mathrm{M}_{\mathrm{n}}=$ $15.8 \mathrm{~kg} \cdot \mathrm{mol}^{-1}$, PDI $=1.05 .{ }^{1} \mathrm{H} \mathrm{NMR}$ (end-group analysis): $\mathrm{M}_{\mathrm{n}}=11.2 \mathrm{~kg} \cdot \mathrm{mol}^{-1}$.

Synthesis of macrochain transfer agent (PLA-O-C(O)-C( $\left.\left(\mathrm{CH}_{3}\right)_{2}-\mathrm{S}-\mathrm{C}(\mathrm{S})-\mathrm{S}-\mathrm{C}_{12} \mathrm{H}_{25}, 3\right)$. Oxalyl chloride $\left(0.071 \mathrm{~mL}, 8.2 \times 10^{-4}\right)$ and $\mathbf{1}\left(0.2 \mathrm{~g}, 5.5 \times 10^{-4}\right)$ were mixed in dry $\mathrm{CH}_{2} \mathrm{Cl}_{2}$ ( $5 \mathrm{~mL}$ ) and stirred at room temperature until gas evolution stopped ( $2 \mathrm{~h})$. After volatiles were removed under vacuum, the residue was redissolved in dry $\mathrm{CH}_{2} \mathrm{Cl}_{2}(10 \mathrm{~mL})$ and 2 ( $3 \mathrm{~g}$ in $20 \mathrm{~mL}$ of $\mathrm{CH}_{2} \mathrm{Cl}_{2}$ ) was added. The mixture was stirred under nitrogen for 16 hours, after which the contents were precipitated in methanol. The polymer was redissolved in $\mathrm{CH}_{2} \mathrm{Cl}_{2}$, precipitated in pentane, and dried in a vacuum oven overnight. Yield $=2.8 \mathrm{~g}$ (93\%). ${ }^{1} \mathrm{H}$ NMR: Conversion $=100 \%$. 
Synthesis of PLA-PDMA (4). N,N-Dimethylacrylamide (0.2 mL), 3 (0.2 g), AIBN (0.29 $\mathrm{mg})$ and DMF $(0.4 \mathrm{~mL})$ were mixed in a reaction vessel and degassed by 3 freeze-pumpthaw cycles. The tube was sealed and placed in an oil bath at $60{ }^{\circ} \mathrm{C}$. After 1 hour, the mixture was diluted with $\mathrm{CH}_{2} \mathrm{Cl}_{2}$ and precipitated in pentane 3 times. ${ }^{1} \mathrm{H}$ NMR:

Conversion $=28 \%$. SEC (PS stds): $\mathrm{M}_{\mathrm{n}}=18.8 \mathrm{~kg} \cdot \mathrm{mol}^{-1}, \mathrm{PDI}=1.10$.

Synthesis of PLA-PDMA-PS. Styrene $(0.44 \mathrm{~mL})$ and $4(0.1 \mathrm{~g})$ were mixed in a reaction tube and degassed by 3 freeze-pump-thaw cycles. The tube was then sealed and placed in an oil bath at $120{ }^{\circ} \mathrm{C}$ for 6 hours. The mixture was diluted with $\mathrm{CH}_{2} \mathrm{Cl}_{2}$ and precipitated in methanol. ${ }^{1} \mathrm{H}$ NMR: Conversion $=51 \%$. SEC (PS stds): $\mathrm{M}_{\mathrm{n}}=45.5 \mathrm{~kg} \cdot \mathrm{mol}^{-1}$, PDI $=$ 1.12 .

Measurements. All ${ }^{1} \mathrm{H}$ NMR spectra were recorded on a Varian VI-500 spectrometer. Size exclusion chromatography (SEC) data was obtained using an HP 1100 series liquid chromatography system equipped with a set of Jordi columns $\left(10^{5}, 10^{3}\right.$ and $\left.500 \AA\right)$ and an HP 1047A RI detector. Tetrahydrofuran $\left(35^{\circ} \mathrm{C}, 1 \mathrm{~mL} \cdot \mathrm{min}^{-1}\right)$ was used as a mobile phase. Differential scanning calorimetry (DSC) analysis was performed on a TA Instruments Q1000 at $10^{\circ} \mathrm{C} \cdot \mathrm{min}^{-1}$. Thermogravimetric analysis data was obtained from a PerkinElmer TGA $7\left(\mathrm{~N}_{2}, 10^{\circ} \mathrm{C} \cdot \mathrm{min}^{-1}\right)$. SAXS experiments were run on a home-built beamline at the University of Minnesota. ${ }^{3}$ SEM images were obtained using a Hitachi S-900 FESEM.

\section{References:}

1. Schmidt, S.C.; Hillmyer, M.A. Macromolecules 1999, 32, 4794.

2. Lai, J.T.; Filla, D.; Shea, R. Macromolecules 2002, 35, 6754.

3. Zalusky, A.S.; Olayo-Valles, R.; Wolf, J.H.; Hillmyer, M.A. J. Am. Chem. Soc. 2002, 124, 12761. 


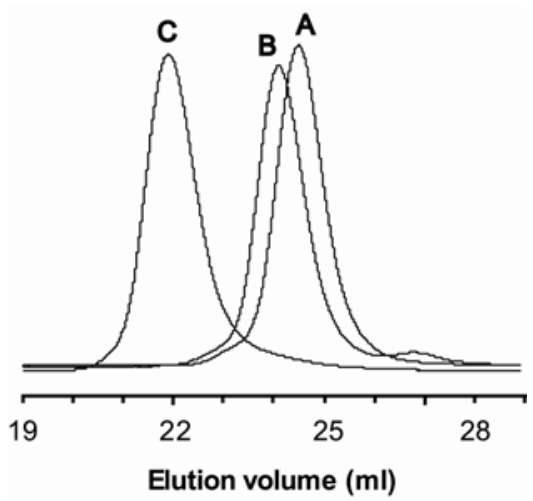

Figure S1. GPC curves for PLA (A), PLA-PDMA (B) and PLA-PDMA-PS (C).

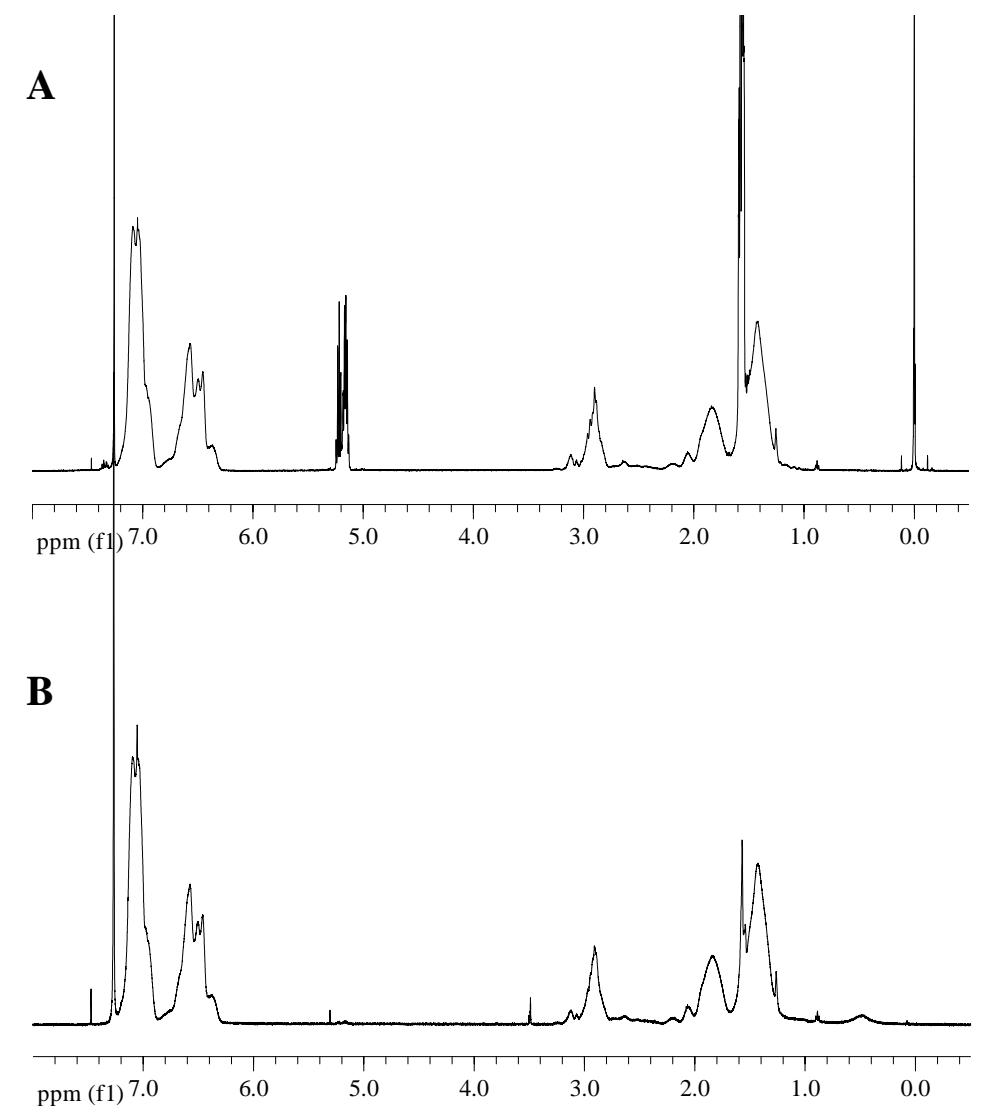

Figure S2. ${ }^{1}$ H NMR spectra of the PLA-PDMA-PS triblock copolymer before (A) and after (B) basic hydrolysis. 


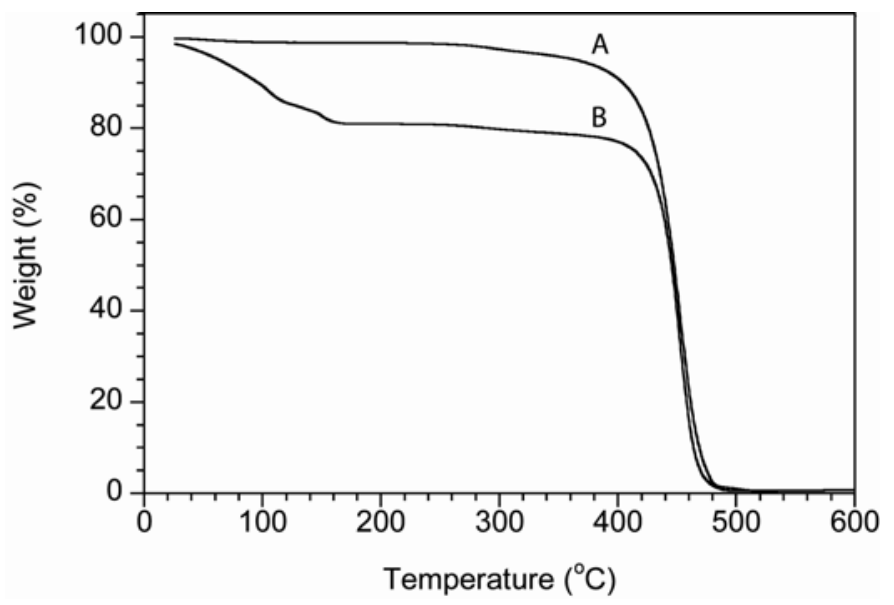

Figure S3. Thermogravimetric analysis of the nanoporous PDMA-PS monoliths before (A) and after (B) soaking in water.

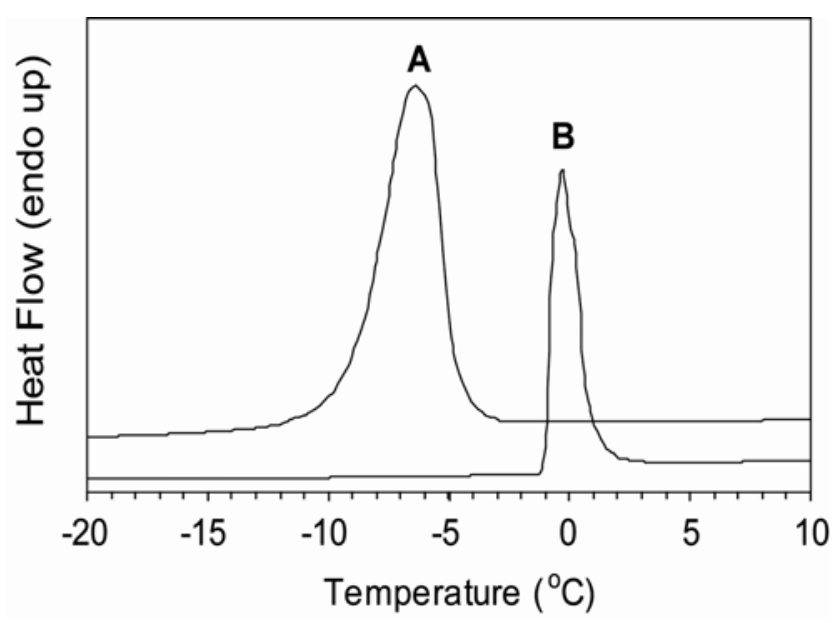

Figure S4. Melting point transition (DSC) of the ice confined in the nanoporous PDMA-PS (A) compared to that of bulk ice (B). 